\title{
Resistência bacteriana aos antibióticos e Saúde Pública: uma breve revisão de literatura
}

\section{Anderson Luiz Pena da Costa ${ }^{1}$ e Antonio Carlos Souza Silva Junior ${ }^{2}$}

\begin{abstract}
1 Acadêmico do Curso de Graduação em Ciências Biológicas da Universidade Federal do Amapá, com período sanduíche nos Estados Unidos na Missouri University of Science and Technology. Brasil. E-mail: pena.biologo@gmail.com

2 Mestre em Ciências da Saúde e graduado em Ciências Biológicas pela Universidade Federal do Amapá. Analista de Meio Ambiente/Pesquisador do Instituto de Pesquisas Científicas e Tecnológicas do Estado do Amapá. Professor do Instituto Macapaense do MeIhor Ensino Superior, Brasil. E-mail: jr_bio2005@yahoo.com.br
\end{abstract}

RESUMO: Nesta revisão de literatura, elaborada a partir da análise de 73 trabalhos científicos, é introduzido ao leitor aspectos farmacodinâmicos dos antibióticos, seus usos terapêuticos (humano e veterinário), nas produções animal e industrial, e as limitações que a resistência bacteriana impõe à utilização destes fármacos em diferentes âmbitos. Sendo os mecanismos bioquímicos e genéticos da resistência bacteriana, assim como os fatores econômicos, sociais, propedêuticos, terapêuticos e epidemiológicos associados ao aparecimento de patógenos resistentes e o ônus que tais organismos geram sobre a saúde pública, o foco deste trabalho.

Palavras-chave: Ciência e Saúde, Saúde Pública, Resistência Bacteriana

Bacterial resistance to antibiotics and public health: a brief literature review

ABSTRACT: In this literature review, which was elaborated from the analysis of 73 scientific papers, the reader is introduced to the pharmacodynamics aspects of antibiotics, their therapeutic uses (human and veterinary), in livestock and industrial production, and the limitations that the bacterial resistance impose to the utilization of these drugs in different settings. In this context, the biochemical and genetic mechanisms of bacterial resistance, as well as the economic, social, propaedeutic, therapeutic and epidemiological factors associated with the appearance of resistant pathogens and the burden that these organisms generate over the public health are the focus of this work.

Keywords: Science and Health, Public Health, Bacterial Resistance

\section{INTRODUÇÃO}

Os antibióticos são fármacos que revolucionaram o tratamento de doenças infecciosas causadas por bactérias e reduziram mundialmente as taxas de morbidade e mortalidade associadas a infecções bacterianas. Entretanto, o mau uso desses fármacos acelera o processo natural de resistência das bactérias contra os antibióticos, devido ao fato de que no ambiente natural esses antimicrobianos são produzidos por populações microbianas como ferramenta de competição por recursos nutricionais e espaço dentro do micro-habitat que ocupam.

Sendo preocupante a forma como esses medicamentos são utilizados em ambientes ambulatoriais, hospitalares e domésticos no tratamento ou profilaxia de doenças humanas; na pecuária (MEIRELES., 2008), como por exemplo, para a produção de animais de corte como frangos (ALLIX, 2010) e para o tratamento de mastite em bovinos (SILVA et al., 2012); e da utilização de produtos 'banais', sem finalidade terapêutica que possuem em suas formulações antibióticos que favorecem a seleção de patógenos re- 
sistentes no meio ambiente e que podem causar doenças de dificil tratamento dentro das comunidades (ORÚS et al., 2015) .

Em termos de saúde pública, a resistência bacteriana representa um risco à qualidade de vida humana conquistada ao longo dos anos com o avanço da microbiologia, das engenharias, da farmácia e da medicina, comprometendo o orçamento dos sistemas de saúde, sejam eles públicos ou privados, além de intensificar outro problema de saúde pública de grande relevância: as infecções hospitalares.

Segundo Oliveira e Silva (2008), as infecções hospitalares estão associadas a falhas nos procedimentos de biossegurança como a utilização de equipamentos de proteção individual, lavagem das mãos, técnicas de assepsia, ineficiência dos controles microbiológicos e de vigilância de pacientes sob suspeita ou risco de infecção causada por patógenos resistente, assim como o isolamento não apropriado de paciente contaminados, deficiência ou carência do serviço de atenção farmacêuticas às prescrições médicas e de atenção farmacêutica ao paciente usuário de antibióticos, que não recebe do profissional farmacêutico as devidas orientações sobre a sua patologia e a prescrição do fármaco, sua concentração, forma de uso, duração do tratamento e forma de armazenamento do medicamento (FERRACINI et al., 2014; GURGEL; CARVALHO, 2008)

Os fatores acima citados resultam em maiores complicações clínicas na recuperação de pacientes hospitalizados, risco para os pacientes acometidos por doença crônica, imunossuprimidos, propiciando um número maior de óbitos nos hospitais (SANTOS, 2004), que podem se tornar reservatórios de patógenos, expostos a um grande número de indivíduos, passíveis de contrair doenças causadas por eles.

Neste contexto, são expostos, a seguir os mecanismos de resistência bacteriana, bem como os aspectos biológicos da resistência microbiana aos antimicrobianos, e sua relação com a saúde pública; também são apresentadas considerações do autor quanto ao fenômeno da seleção natural e da resistência biológica.

\section{METODOLOGIA}

Este trabalho é uma revisão de literatura do tipo narrativa, que não utilizou critérios explícitos e sistemáticos para a busca e análise crítica de literatura. Na qual, para a elaboração do trabalho, inicialmente foi realizado um mapeamento de material cientifico literário, que resultou num total de 73 obras, incluindo artigos, resumos, livros, teses e dissertações, disponíveis na internet, cujos temas abordassem antibióticos e a resistência bacteriana, utilizados para a construção de uma contextualização da problemática e das possibilidades presentes na literatura.

Após a análise literária, foram selecionados 37 dos 73 trabalhos lidos para embasar o corpo dessa revisão, cuja a exposição dos dados e interpretação das informações contidas nos trabalhos lidos, estão sujeitas à subjetividade dos autores.

\section{REVISÃO DE LITERATURA}

\subsection{Antibióticos}

Os antibióticos são uma classe de fármacos utilizados para o tratamento de doenças infecciosas, que diferem uns dos outros quanto as suas propriedades físicas, 
químicas, farmacológicas, no espectro e mecanismo de ação. (BAPTISTA, 2013). Havendo critérios muito importantes que devem ser considerados para que a terapia de doenças bacterianas com antibióticos venha a ser eficaz, como a necessidade de que um alvo (ligante) exista dentro da célula bacteriana, a concentração do antibiótico alcance o alvo em quantidade suficiente, não podendo ocorrer inativação ou modificação estrutural do fármaco (COSTA, 2016).

Segundo Batista (2013), o antibiótico ideal seria um fármaco com alvo seletivo, ação bactericida rápida, espectro de ação estreito que não afete a microbiota saprófita, com baixo nível tóxico e elevados níveis terapêuticos, poucas reações adversas, várias vias de administração, boa distribuição no local de infecção e ser um antibiótico que não contrarie as defesas imunológicas do hospedeiro, não induza resistência e possua boa relação custo/eficácia. Sendo, no entanto, todas essas características, difíceis de serem obtidas devido a relação entre os antibióticos e as bactérias, não ser linear (COSTA, 2016).

De acordo com Guimarães et al. (2010) , os antibióticos podem ser classificados 1) de acordo com suas origens em antibióticos naturais, quando são obtidos a partir de organismos vivos; antibióticos semisintéticos, que são substâncias de origem natural que são submetidas a processos de síntese em laboratório; ou antibióticos sintéticos, que são produzidos exclusivamente em laboratório; 2) pela suas ações sobre as células bacterians (bacteriostáticos ou bactericidas; ou 3) pelo seus mecanismos farmacodinâmicos, que podem ser os seguintes:

- Inibição da síntese de parede celular: Os antibióticos com este mecanismo de ação atuam ao nível da síntese do peptidoglicano, impedindo sua síntese. Antibióticos que exemplificam este mecanismo de ação são os $\beta$-lactâmicos como a penicilina e as cefalosporinas, que inibem enzimas necessárias para a formação do peptidoglicano; a bacitracina que bloqueia a passagem do pirofosfato-bactoprenol à fosfobactoprenol (BAPTISTA, 2013) que é um importante precursor da síntese de parede celular e carreador de membrana associado a processos anabólicos em gram-positivos (SCHNEIDER et al., 2009); e os glicopeptídeos como a vancomicina que se liga à extremidade terminal do peptídeo D-Ala-D-Ala da cadeia do peptidoglicano, prevenindo as ligações cruzadas entre o $\mathrm{N}$-acetilglucasamina e o ácido $\mathrm{N}$-acetilmurâmico que formam o peptidoglicano da parede celular (DZIDIC et al., 2008; BAPTISTA, 2013).

- Inibição da síntese proteica: Os ribossomos bacterianos são organelas celulares constituídas por duas subunidades, 30s e 50s, onde ocorre a síntese de proteínas, atuando fármacos como os aminoglicosídeos, tetraciclinas, cloranfenicol, macrólitos, licosamida e oxazolinidonas, inibindo ou modificando o processo de síntese de proteínas, se ligando a uma das duas subunidades formadoras do ribossomo, impedindo assim a síntese de enzimas necessárias ao metabolismo e impedindo também o crescimento bacteriano (COSTA, 2016).

- Inibição da síntese de ácidos nucleicos: Antibióticos que exemplificam este mecanismo de ação são as quinolonas como a ciprofloxacina, norfloxacina e ofloxacina que inibem as enzimas girase e topoisomerase IV que atuam no processo de replicação do DNA (COSTA, 2016) e a rifampicina que atua inibindo a RNA polimerase, que é responsável pelo processo de transcrição, 
impedindo a síntese de mRNA e consequentemente a de proteínas (DZIDIC et al., 2008).

- Desorganização da membrana celular: Antibióticos que exemplificam esse mecanismo de ação são as polimixinas que são moléculas anfipáticas tensoativas que interagem com as moléculas de polissacarídeos presentes na membrana externa, sequestrando o cálcio e o magnésio necessário para a estabilidade da membrana, desorganizando-a, alterando sua permeabilidade e causando vazamento do conteúdo intracelular (DZIDIC et al., 2008).

- Interferência no metabolismo celular: As sulfonamidas e o trimetropim bloqueiam diferentes etapas da síntese de folato, que é um cofator necessário para a síntese de DNA e RNA (DZIDIC et al., 2008), impedindo que os processos celulares ocorram.

Os antibióticos representam para a medicina um grande avanço por tornarem possíveis a realização de procedimentos invasivos como cirurgias, transplantes, partos prematuros e terapias citotóxicas para o câncer, dentre outros procedimentos profiláticos ou terapêuticos que contribuem para o aumento da expectativa de vida das populações humanas do planeta (BRITO; CORDEIRO, 2012), que pode ser comprometido pela resistência bacteriana aos antibióticos por reduzir as opções de fármacos efetivos contra patógenos bacterianos e favorecer a disseminação de bactérias resistentes dentro de ambientes hospitalares e na comunidade.

Neste contexto, se faz importante o desenvolvimento de materiais educativos e campanhas que informem sobre a resistência bacteriana, promovam o uso racional dos antibióticos e axiliem na prevenção de endemias prevalentes, surtos, epidemias e no pior dos cenários pandemias de infecções causadas por bactérias resistentes.

\subsection{Resistência bacteriana e seus aspectos genéticos e bioquímicos}

Com a introdução de fármacos eficientes no combate às infecções, melhoras significantes no tratamento médico das doenças infecciosas foram obtidas, ocasionando em uma considerável redução das taxas de morbidade e mortalidade, permitindo grandes progressos na medicina(COSTA, et al., 2012) Porém o mau uso desses fármacos leva ao aparecimento de micro-organismos resistentes, que se acumulam e se disseminam, representando um sério risco para a população, por reduzirem as opções de fármacos efetivos para o tratamento de infecções, aumentarem as complicações clínicas de pacientes hospitalizados e prolongar o tempo de estadia hospitalar, elevando os custos direcionados à recuperação dos pacientes doentes e com saúde pública (SIQUEIRA, 2004).

A resistência aos antimicrobianos pode ser: 1) uma característica intrínseca de certas espécies de bactérias que podem resistir à ação de um dado antibiótico como resultado de uma característica estrutural ou funcional inerente de dada espécie (BLAIR et al., 2015); 2) ser adquirida como resultado de mutações que podem ocorrer durante a replicação celular ou serem induzidas por intermédio de agentes mutagênicos como radiações ionizantes e não ionizantes, agentes alquilantes ou espécies reativas de oxigênio (ROS) (BAPTISTA, 2013); 3) adquirida pela aquisição de material genético exógeno anteriormente presente em outros micro-organismo que contenham genes de 
resistência que são propagados por meio de mecanismos de transferência gênica horizontal (TAVARES, 2000; COSTA, 2016) como a conjugação bacteriana, a transformação e a transdução (DZIDIC et al., 2008).

Apresentando os micro-organismos portadores de resistência intrínseca ou de genes de resistência, maior adaptação e tolerância a pressão seletiva que os antibióticos impõem ao meio, devido às capacidades bioquímicas que tais micro-organismos podem expressar (KUMAR; VARELA, 2013), que favorecem seu desenvolvimento por reduzir a competição por espaço e nutrientes no meio com as células que não possuem mecanismos de resistência, selecionando os micro-organismos menos suscetíveis ou resistentes aos agentes antimicrobianos dentro de uma comunidade microbiana (GUSTAVO, 2008).

Sendo os mecanismos bioquímicos de resistência aos antibióticos reportados em literatura os seguintes:

- Inativação enzimática do antibiótico: O mecanismo enzimático de resistência ocorre devido a inativação do fármaco a partir da produção, pela bactéria, de enzimas que degradam ou inativam o antibiótico. Envolvendo três tipos de reações enzimáticas, tais como, hidrólise, transferência de um grupo químico ou processo de oxiredução (COSTA, 2016).

O exemplo clássico deste mecanismo de resistência é a produção de $\beta$-lactamase que hidrolisa $o$ anel $\beta$-lactâmico das penicilinas (KUMAR; VARELA, 2013) e cefalosporinas. Havendo muitas bactérias gramnegativas e gram-positivas que produzem tal enzima, existindo identificadas mais de 200 tipos de $\beta$-lactamase pertencentes a diferentes grupos funcionais, que podem ser de origem cromossomal ou de plasmí- deos de bactérias diferentes (KUMAR; VARELA, 2013).

Várias bactérias gram-positivas e gramnegativas produzem $\beta$-lactamases de espectro estendido (ESBLS), que é um dos tipos de $\beta$-lactamases codificadas por genes plasmidiais como o CTX-M, que apresenta muitas variantes e produtos de tradução muito diversos que conferem resistência a todas as penicilinas e cefalosporinas de terceira geração, mas não as cefamicinas e carbapenêmicos (BLAIR et al., 2015). Havendo registrado em literatura a ocorrência de mas de 180 ESBLs identificadas, que são comumente detectadas em Escherichia coli, Klebsiella pneumoniae, Proteus mirabilis e outras bactérias da família Enterobacteriaceae (BAPTISTA, 2013), e também em bactérias como Pseudomonas aeruginosa e Acinetobacter baumannii (BLAIR et al., 2015).

A inativação de antimicrobianos por meio de reações como $O$-acetilação, $N$ acetilação, $O$-fosforilação, $O$-nucleodilação, $O$-ribosilação, $O$-glicosilação e transferência de grupos tiol, catalisadas por transferases dependentes de co-substratos como ATP, acetil - Coenzima A, NAD ${ }^{+}$, UDP-glicose ou glutationa (BAPTISTA, 2013) é um mecanismo de resistência que afeta várias classes de antibióticos como os macrolídeos, aminoglicosídeos, anfenicóis, fosfomicina e estreptograminas (COSTA, 2016), formando as enzimas responsáveis por este processo de adição de grupos químicos a sítios vulneráveis da molécula de antibiótico, uma grande família de enzimas de resistência a antibióticos (BLAIR et al., 2015).

Enzimas como a cloranfenicol aciltransferases, aminoglicosídeos acetiltransferases, virginamicina acetiltranferases e macrolídeo quinases são 
transferases que conferem respectivamente resistência ao cloranfenicol, aminoglicosídeos, estreptograminas e macrólideos, e podem ser detectadas em bactérias como Staphylococcus aureus, Serratia marcescens, Escherichia coli e Pseudomonas aeruginosa (KUMAR; VARELA, 2013).

A inativação da molécula de antibiótico por meio de oxidação ou redução catalisada por enzimas bacterianas também constitui um mecanismo de resistência, como por exemplo, a enzima TeTX (BAPTISTA, 2013) que na presença de flavina transfere um único grupo hidroxil à molécula de tetraciclina na posição 11 a , resultando em uma estrutura menos apta para sequestrar íons $\mathrm{Mg}^{+}$que são críticos para a tetraciclina atingir seu alvo (subunidade 30 s do ribossoma bacteriano), e então poder inibir o crescimento bacteriano pela inibição da síntese proteica (KUMAR; VARELA; 2013).

- Modificação do alvo do antibiótico: A maioria dos antibióticos se liga especificamente aos seus alvos com alta afinidade e dessa forma previnem a atividade normal do alvo. Entretanto mudanças estruturais do alvo que previnem a ligação efetiva entre o alvo e o antibiótico, mas que ainda possua sua função normal conferem resistência (BLAIR et al., 2015).

As proteínas ligadoras da penicilina (PBP), que são responsáveis pela ligação cruzada entre os polímeros de ácido $\mathrm{N}$ acetilmurâmico e $\mathrm{N}$-acetilglucosamina precursores do peptidoglicano formador da parede celular, quando apresentam mutações nos genes que as codificam, produzem PBPs estruturalmente diferente (as PBPa2) que apresentam afinidade ao fármaco extremamente reduzida, não havendo o lise celular, pois a droga não irá interferir na ligação cruzada dos dois polímeros que formam a parede celular bacteriana (SIQUEIRA, 2004; GUSTAVO, 2008). Sendo este mecanismo de resistência reportado em Staphylococcus aureus portadores do elemento genético móvel chamado $\mathrm{SCCmec}$ que possui o gene mecA, que confere resistência a meticilina (DZIDIC et al., 2008).

Modificações dos aminoácidos D-alaninaD-alanina da extremidade terminal do peptidoglicano por D-alanina-D-lactato ou Dalanina-D-serina reduzem consideravelmente a afinidade da droga com seu sítio de ligação que se torna repulsivo ao antibiótico que não afetará a célula bacteriana (SILVEIRA et al., 2006; GUSTAVO, 2008). Encontrando-se comumente este mecanismo contra glicopeptídeos (vancomicina) de forma bastante disseminada em bactérias gram positivas por meio de replicação de clones bacterianos, ou transferência horizontal de genes. Podendo a resistência a vancomicina se apresentar como resistência intrínseca (tipo VanC) em algumas espécies ou adquirida (tipos VanA, B, E e G) (DZIDIC et al., 2008).

- Bombas de efluxo: Bombas de efluxo são proteínas membranares que exportam os antibióticos para o meio extracelular, mantendo as concentrações intracelulares em baixos níveis. Sendo este um mecanismo de resistência que afeta todas as classes de antibióticos, atingindo principalmente os macrólitos, tetraciclinas e fluoroquinolonas (DZIDIC et al., 2008), podendo ser detectado tanto em bactérias gram positivas quanto gram-negativas, podendo ser associado a este mecanismo de resistência um número significativo de genes que codificam para diferentes transportadores de antibióticos como os genes mef, msr e vga em cocos gram-positivos resistentes a macrólitos, lincosamina e estreptogramina B, o gene 
TET relacionado à resistência a tetraciclina, o gene acrR codificador do sistema de efluxo AcrAB-TolC encontrado em Escherichia coli e outras bactérias gram-negativas e também em gram-positivas (BAPTISTA, 2013).

Existindo diversos tipos de bombas de efluxo que são categorizadas em cinco classes de transportadores, havendo as que atuam por meio de transporte ativo e as que atuam por transporte ativo secundário (KUMAR; VARELA, 2013), respectivamente pela hidrólise de ATP como o transportador adenosine triphosphate binding cassette $(A B C)$ e pela manutenção do gradiente iônico intracelular como os transportadores major facilitator family (MFS), multidrug and toxic efflux (MATE), resistance nodulation division (RND), small multidrug resistance (SMR) (BAPTISTA, 2013).

- Alteração da permeabilidade da membrana: Os fármacos podem penetrar a membrana celular por meio de três formas 1) por difusão simples através da bicamada fosfolipídica; 2) por difusão facilitada mediada por proteínas membranares chamadas porinas ou 3) self promoted uptake. Onde a penetração do fármaco nas bactérias depende de características físico-químicas dos antibióticos como a polaridade e o tamanho das moléculas (BAPTISTA, 2013). Modificações no conteúdo de lipopolissacarídeos (LPS) e estrutura e quantidade de porinas alteram a permeabilidade de fármacos como $\beta$-lactâmicos, aminoglicosídeos, cloranfenicol e fluoroquinolonas em bactérias gram-negativas (DZIDIC et al., 2008).

- Formação de biofilmes: A produção de biofilmes é considerada de acordo com Kuma et al. (2013) um novo modo de resistência, capaz de ocorrer em muitos lugares, incluindo a placa dentária, ambientes aquá- ticos, catéteres médicos, feridas traumáticas e outros, onde os micro-organismos encontrados nos biofilmes são protegidos contra a entrada de múltiplos agentes antimicrobianos. Ocorrendo a formação de biofilmes em duas fases distintas que são (1) a adesão primária das células a uma superfície, (2) seguida da formação de microcolônias que se acumulam agrupadas em multicamadas celulares e iniciam a síntese da matriz extracelular primária que formará o biofilme, sendo esta matriz primária composta principalmente de proteínas e polissacarídeos. Havendo intensa comunicação química via quorum sesing entre as células bacterianas, que coordenadamente tem seus genes responsáveis pela síntese de exopolissacarídeos ativados, ocorrendo após certo grau de crescimento microbiano, a formação um agregado de células embutidas em uma matriz de exopolissacarídeos que constitui o biofilme maduro (SOUZA et al., 2011).

Comportando-se as células sésseis que vivem em biofilmes de forma diferente das células planctônicas fisiologicamente, fenotipicamente e metabolicamente, sendo inclusive mais resistentes a fatores estressores que incluem substâncias biocidas (SOUZA et al., 2011), tornando-se os biofilmes microbianos um desafio na área da medicina por reduzir o potencial das quimioterapias com antimicrobianos ou anular seu efeito, também diminuindo a qualidade de vida de portadores de próteses médicas, e pacientes hospitalizados cateterizados (GESTAL; HOLBAN, 2014).

\section{RESISTÊNCIA MICROBIANA E SAÚDE PÚ- BLICA}

A resistência microbiana é um problema 
de saúde pública associado a diversos fatores e fasciculado entre os sistemas de saúde de todo o mundo, sendo a resistência bacteriana segundo a World Economic Forum Global Risks listada como uma das grandes ameaças à saúde humana (BLAIR et al., 2015), tornando-se relevante considerar de forma multidisciplinar o maior número possível de pontos estratégicos de ação, contemplando desde a natureza das doenças infecciosas, os procedimentos farmacoterapêuticos existentes, os fatores ambientais, políticos e sócio-econômicos pertinentes à questão, visto que não há uma solução definitiva para a resistência microbiana em função da dinamicidade da evolução biológica dos organismos vivos.

Toda infecção acontece após um agente biológico aderir-se, invadir, esquivar-se das defesas imunológicas do hospedeiro e com sucesso colonizar seus tecidos, ocorrendo a doença em função de lesões causadas pelo agente aos tecidos e órgãos do hospedeiro que sistemicamente terá comprometida todas as suas funções fisiológicas, caso não disponha de meios de defesa e proteção contra os patógenos que nele tentarão se estabelecer e dele obter nutrientes e condições fisiológicas desejadas (CUNHA et al, 2008), manifestando-se a doença (sinais e sintomas) em períodos (incubação, prodrômico, transmissibilidade e convalescência) que são definidos pela biologia de cada patógeno e sua relação com o hospedeiro.

Neste contexto, o planejamento, organização e execução de ações educativas de saúde, contenção e preventivas da disseminação de patógenos resistentes ou não em ambientes hospitalares, laboratoriais, ambulatoriais e domésticos depende do reconhecimento dos períodos da doença citados acima, assim como 1) as fontes de infecção, ou seja, todos os hospedeiros e meios que podem manter um agente infeccioso viável e apto para infectar novos hospedeiros; 2) as vias de eliminação, ou seja, as formas pelas quais pode ocorrer a saída de um agente infeccioso a partir de uma fonte de infecção, como por exemplo, as secreções naso-buco-faríngeas, as fezes, urina, sangue, escarro, exudatos, descargas purulentas, descamações epiteliais, o suor, o leite materno e outras vias como a placentária e a via sexual; e 3) as vias de transmissão que são os meios pelos quais o hospedeiro interage com o agente causador de doença, (LESSER et al., 1985), além da análise de inúmeras variáveis, como por exemplo, condições e alterações ambientais, condições demográficas, socioeconômicas e políticas relacionadas à qualidade das políticas de saúde e da organização dos sistemas e serviços de assistência médica prestada à comunidade, que podem contribuir para a dispersão de um dado patógeno dentro de uma população (SAKER et al., 2004).

O reconhecimento dos fatores de suscetibilidade e resistência às doenças intrínsecas aos indivíduos de uma dada população são características que também devem ser consideradas pelos sistemas de vigilância em saúde, para que os padrões de transmissão das doenças infecciosas sejam elucidados, e se aplicável, programas de vacinação sejam organizados e executados com foco na fração crítica da população com o intuito de eliminar determinado patógeno e alcançar redução máxima de doenças, prevenindo a formação de fontes de infecção (LEVEIN et al., 1999).

Em relação aos fatores epidemiológicos relevantes para o controle das doenças infecciosas, é importante ressaltar, que no Brasil, os programas, treinamentos, manu- 
ais, RDCs e guias disponibilizados nacionalmente destinados ao combate de patógenos resistentes são baseados em documentos de origem internacional como a Food and Drug Administration, Center for Disease Control, World Health Organization e o National Committee for Clinical Laboratory Standards, literaturas essas, que consideram a presença de muitos recursos, assim como condições patológicas não presentes na realidade nacional (COSTA, 2016) representam limitações para as ações de controle e prevenção da resistência microbiana e disseminação de patógenos resistentes em comunidades humanas, em função da discrepância sócio-econômica dos países onde a literatura de referência é publicada, e o Brasil. Neste âmbito, pode-se afirmar que trabalhos baseados na realidade nacional, regional e de cada estado do país, em relação à incidência e prevalência de casos de infecções causadas por patógenos resistentes nos estabelecimentos de saúde podem nortear o planejamento e a logística das ações e serviços de saúde como vigilância ambiental e vigilância sanitária, favorecendo a execução de estratégias institucionais, administrativas, programáticas e sociais fundamentadas em políticas públicas especificamente desenvolvidas para reduzir e prevenir os riscos à saúde mais comuns, em cada localidade (OLIVEIRA; CRUZ, 2015)

Em relação à prática dos profissionais de saúde, entre os fatores que contribuem para a resistência microbiana estão a postura defensiva de profissionais de saúde que prescrevem antimicrobianos desnecessariamente com finalidade de evitar potenciais complicações jurídicas (MEIRELES, 2008), e a prescrição baseada empiricamente em sinais e sintomas sem fundamentação em culturas microbianas e testes de suscetibili- dade, sendo estes os principais fatores desencadeadores de patógenos resistentes em ambiente hospitalar, na qual os fármacos antimicrobianos exercem grande pressão seletiva sob cepas resistentes (MENEZES et al., 2007) havendo também vários outros fatores de natureza socioeconômica que influenciam no uso não racional e ou abusivo de antimicrobianos como a pobreza e acesso inadequado a estes fármacos, o que leva muitos pacientes a procurarem produtos de qualidade duvidosa, adulterados, falsificados ou contendo concentrações subterapeuticas do componente ativo (MEIRELES, 2008).

De acordo com Meireles (2008), o uso inapropriado de antimicrobianos não se restringe ao uso médico humano e veterinário, existindo disponível no mercado uma grande diversidade de produtos como sabonetes, detergentes, cremes dentais, escovas de dentes, creme para as mãos e outros produtos contendo agentes antimicrobianos que favorecem a seleção de cepas resistentes dentro do ambiente doméstico, em função da imagem de proteção contra os germes que esses produtos transmitem em suas campanhas midiáticas, atenuando riscos de infecções comunitárias resistentes a agentes antimicrobianos. Ainda em relação a resistência bacteriana e cosméticos, é relatado por Orús (2015) que a exposição de populações microbianas a adjuvantes conservantes presentes em fórmulas de cosméticos é apontada como fator indutor da resistência bacteriana a vários antibióticos, sendo sugerido que ocorra resistência cruzada aos antibióticos em função de uma resposta adaptativa aos adjuvantes biocidas que muitos cosméticos possuem em suas formulações.

O uso de drogas antimicrobianas na agri- 
cultura, pecuária e piscicultura com finalidade profilática e de tratamento (MEIRELES, 2008) também representam um risco à saúde pública por selecionar cepas resistentes que podem colonizar o trato digestivo humano e transferir genes de resistência aos patógenos e comensais humanos que podem se tornar patógenos oportunistas (COSTA, 2016). A utilização dos antibióticos com finalidades veterinária e de produção pecuária, da mesma forma que na medicina humana, está diretamente vinculada com a liberação dessas substâncias no meio ambiente atráves do esgoto doméstico, efluentes hospitalares e industriais, o descarte de medicamentos com prazo de validade expirado e as sobras domésticas daqueles não utilizados (ACURCIO, et al. 2013), que selecionam bactérias resistentes no meio ambiente, principalmente em ambientes aquáticos.

Segundo Moura et al. (2010), "apesar de quase meio século de concentração de esforços, infecções associadas à assistência em saúde permanecem ainda como a principal causa de morbidade e mortalidade e incremento de custos. $O$ tratamento destas infecções vem se tornando mais complexo em virtude do crescimento alarmante da resistência aos antimicrobianos." Sendo, necessariamente, a utilização de antimicrobianos ser cada vez mais restrita.

\section{CONSIDERAÇÕES GERAIS}

Embora a maior parte das atenções tenha sido focada na resistência de patógenos encontrados em pacientes hospitalizados e em bactérias diretamente responsáveis por efeitos adversos à saúde humana, o desenvolvimento da resistência aos antibióticos é um fenômeno ecológico natural, produto de bilhões de anos de evolução que ocorre na ausência de atividade humana, devido à exposição de micro-organismos às substâncias antimicrobianas produzidas por outros micro-organismos, favorecendo a seleção de genes de resistência em espécies ambientais de forma natural, mas que podem ser transferidos para patógenos humanos (BLAIR et al., 2015).

Por conseguinte, medidas para evitar a resistência bacteriana, como o uso racional dos antibióticos, prevenção de infecções bacterianas, controle e prevenção da disseminação de micro-organismos resistentes são essenciais, assim como a busca por novos metabólitos ativos contra diferentes micro-organismos patogênicos devem ser ativas, contínuas (GUIMARÃES et al., 2010; DUARTE et al., 2009).

Pesquisas nas ciências direcionadas ao reconhecimento da biodiversidade e bioprospecção de novos produtos naturais com atividade antimicrobiana (FILHO et al., 2014), a especialização de recursos humanos nas áreas da biologia molecular e das engenharias biológicas são essenciais para o desenvolvimento de novos antimicrobianos (GUIMARÃES et al., 2010), asssim como as nanociências e a nanotecnologia para o meIhoramento dos medicamentos existentes e desenvolvimento de novas formas farmacêuticas como nanoemulsões (JAISWAL et al., 2015), nanopartículas, (SINGH et al., 2014), lipossomas (ZHANG et al., 2010) e dendrímeros (ARAÚJO, 2010) para combater o problema da resistência microbiana.

Em conclusão, a prevenção das doenças infecto parasitárias para ser efetiva requer a realização de boas práticas de higiene por parte da população e medidas profiláticas que considerem a natureza do estímulodoença, fatores ambientais e a interação do 
hospedeiro humano e o estímulo-doença que deve ser eliminado ou ser reduzido a um nível insignificante antes que a interação com o hospedeiro humano ocorra, a identificação do horizonte clínico (sinais e sintomas) das doenças infecciosas quando a interação estímulo-doença e hospedeiro já tenha ocorrido para que a cura seja alcançada e os diferentes graus de incapacitação como morte, cura com defeito e estados crônicos sejam evitados, assim como as causas sociais e as condições socioambientais que promovem as doenças devem ser tópicos abrdados pelos profissionais de saúde de forma holística, multidisciplinar e transdisciplinar, pois o conhecimento e compreensão do fenômeno da resistência bacteriana por parte dos profissionais de saúde os tornam concientes da importancia de suas de práticas individuais, coletivas e suas relações com a problematica trabaIhada, possibilitando por meio de analise crítica do ambiente em que trabalham e suas práticas profissionais contribuir de forma pragmática e eficaz para a reformulação das políticas públicas de saúde (OLIVEIRA; SILVA, 2008).

\section{REFERÊNCIAS}

\section{ALLIX, E. Promotores de Crescimento para}

Frangos de Corte. 29f. Monografia (Curso de Graduação em Medicina Veterinária) UFRGS, Porto Alegre, 2010.

ACURCIO, et al. (Org). Medicamentos: políticas, Assistência Farmacêutica, Farmacoepidemiologia e Farmacoeconomia.1.ed. Belo Horizonte, 2013. 319 p.

ARAÚJO, L. M. P. C. Dendrímeros como Carreadores da Protoporforina IX para Terapia Fotodinâmica Tópica do Câncer de Pele. 58f. Monografia (Doutorado em Ciências
Farmacêuticas), Programa de PósGraduação em Ciências Farmacêuticas, USP, São Paulo, 2010.

BAPTISTA, M. G. F. M. Mecanismos de Resistência aos Antibióticos. 2013. 42f. monografia (Dissertação de Mestrado) - Curso de Mestrado Integrado em Ciências Farmacêuticas, Universidade Lusófona de Humanidades e Tecnologia, Lisboa.

BLAIR, J. M. et al. Molecular Mechanisms of Antibiotic Resistance. Nature, v. 13, p. 4251, 2015.

BRITO, M. A., CORDEIRO, B. C. Necessidade de Novos Antibióticos. Jornal Brasileiro de Patologia Med Lab, v. 48, n. 4, p. 247-249, 2012.

COSTA, A. L. P. et al. Analise qualitativa fitoquímica e do potencial antimicrobiano do extrato bruto de casca de bertholletia excelsa humb. \& bomple (lecytgidaceae) frente a microrganismos gram-positivos. Ciência Equatórial, v.22, p. 26-34, 2012.

COSTA, A.L.P. Resistência Bacteriana aos Antibióticos: Uma Perspectiva Do Fenômeno Biológico, Suas Consequencias e Estratégias De Contenção. 63 f. Trabalho de Conclusão de Curso (Graduação em Biologia) Curso de Ciências Biológicas, Departamento de Ciências Biológicas e da Saúde, UNIFAP, Macapá, 2016.

CUNHA, S. et al. Doenças Infeciosas: $O$ desafio da Clínica. Coimbra, 2008.

DUARTE, M. W. Et al. Atividade Antimicrobiana e Produção e Enzimas Extracelulares por Actinomicetos Isolados de Solo. $33 \mathrm{f}$. Trabalho de Conclusão de Curso (Graduação em Ciências Biológicas) - Curso de Ciências Biológicas, Departamento de Microbiologia, Instituto de Ciências Básicas e da Saúde, UFRGS, Porto Alegre, 2009

DZIDIC, S.; SUSKOVIC, J.; KOS, B. Antibiotic Resistance Mechanisms in Bacteria: Bio- 
chemical and Genetic Aspects. Food Technology and Biotechnology. v. 46, n. 11, p. 11-21, 2008.

FILHO, S. A.; SILVA, C. G. N.; BIG, M. F. M. A. Bioprospecção e Biotecnologia. Parcerias Estratégicas. v. 19, n. 38, p. 45-80, 2014. FERRACINI, F.T.; FILHO, W.M.B.; ALMEIDA, S.M. Atenção à Prescrição Médica, 1.ed. São Paulo, Atheneu, 2014.

GESTAL; HOLBAN. Advances in Nanotechnology as an Alternative Against Superbugs, JSM Chemistry. SciMed Central, v .2, n. 2, p. 1-5, 2014.

GUIMARÃES, D. O.; MOMESSO, L. S.; PUPO, M. T. Antibióticos: Importância Terapêutica e Perspectivas para a Descoberta de Novos Agentes. Química Nova, v. 33, n. 3, p. 667679, 2010.

GURGEL, T. C.; CARVALHO, W. S. A Assistência Farmacêutica e o Aumento da Resistência Bacteriana aos Antibióticos. Latin American Journal of Pharmacy, n. 27, v. 1, p. 118-123, 2008.

GUSTAVO. B. L. Análise de portadores assintomáticos de staphylococcus aureus no hospital universitário de Brasília. 2008. 102f. Monografia (Dissertação de Mestrado) - Programa de Pós-Graduação em Patologia Molecular da Faculdade de Medicina da Universidade de Brasília, Brasília.

JAISWAL, M.; DUDHE, R.; SHARMA, P. K. Nanoemulsion: An Advanced Mode of Drug Delivery System. Biotechnology, Spring, v. 5., p. 123-127, 2015.

KUMAR, S., VARELA, M. F. Molecular Mechanisms of bacterial Resistance to antimicrobial Agents. Microbial Pathogens and strategies for Combating Them: Science, technology and education, Formatex, p. 5225342013.

LEVEIN, B. R.; LIPSITCH, M.; BONHOEFFER, S. Population Biology, Evolution and Infec- tious Diseases: Convergence and Synthesis. Science, v. 283, pag 806-809, 1999.

LESER, W.; BARBOSA, V.; BARUZZI, R.G.; Elementos de Epidemiologia Geral, Ed. Atheneu, Rio de Janeiro, 1985

MEIRELES, M. A. O. M. Uso de Antimicrobianos e Resistência Bacteriana: Aspectos Socioeconômicos e Comportamentais e seu Impacto Clínico e Ecológico. 2008. 47f. Monografia (Especialização em Microbiologia) - Universidade Federal de Minas Gerais, Belo Horizonte.

MENEZES, F. G. et al. Evolução da Farmacoterapia de Antibióticos em Pacientes com Infecção hospitalar. Saúde Coletiva, v. 4, n. 15, p. 84-88, São Paulo, 2007.

MOURA, P. M. et al. Resistência à mupirocina entre isolados de Staphylococcus aureus de profissionais de enfermagem. Acta Paulista Enfermagem, v. 23, n. 3, p. 399-403, 2010.

OLIVEIRA, C. M.; CRUZ, M. M. Sistemas de Vigilância em Saúde no Brasil: Avanços e Desafios. Saúde Debate, n. 104, v. 39, p. 255-267, 2015.

OLIVEIRA, A. C.; SILVA, R. S. Desafios do Cuidar em Saúde Frente à Resistência Bacteriana: Uma Revisão. Revista Eletrônica de Enfermagem, n. 10, v. 1, p. 189-197, 2008.

ORÚS, P. et al. Increasing Antibiotic Resistance in Preservative-Tolerant Bacterial Strains Isolated from Cosmetic Products. International Microbiology, n.18, p. 51-59, 2015

SAKER., L. S. et al. Globalization and Infectious diseases: a review of the linkages. UNICEF/UNDP/WORLD BANK/WHO Special Program for Research and Training in Tropical Diseases. 2004.

SANTOS, N. Q. A. Resistência Bacteriana no Contexto da Infecção Hospitalar. Texto Contexto Enfermagem, v. 13, n. Especial, p. 
64-70, 2004.

SILVEIRA, G. P. et al Estratégias Utilizadas no Combate à Resistência Bacteriana. Química Nova, v. 29, n. 4, p. 844-855, 2006.

SILVA, R. M.; SILVA, R. C.; RIBEIRO, A. B. Resíduos de Antibióticos em Leite. Revista Saúde e Biologia. v.7, n.1, p. 30-44, 2012.

SOUZA, C; BOTELHO, C.; OLIVEIRA, R. Nanotechnology Applied to Medical Biofilms Control. Science Against Microbial Pathogens: Communicating Current Research and Technological Advances, Formatex, $p$. 878-888, 2011.

SINGH, R.; SMITHA, M. S.; SINGH, S. P. The Role of nanotechnology in Combating Multi-Drug Resistant Bacteria. Journal of Nanoscience and Nanotechnology, v.14, n.10, p. 177-184, 2014.

SCHNEIDER, T. et al. The Lipopeptide Antibiotic Friulimicin B Inhibits Cell Wall Biosynthesis through Complex Formation with Bactoprenol Phosphate. Antimicrobial Agents and Chemotherapy, v. 53, n. 4, p. 1610-1618, 2009.

SIQUEIRA, C. M. M. Resistência aos Antibióticos: $\mathrm{O}$ uso inadequado dos antibióticos na prática clínica. Resista de la Organización de Farmacéuticos Iberoamericanos, v. 14, n. 1, p. 45-68, 2004.

TAVARES, W. Bactérias gram-positivas problemas: resistência do estafilococo, do enterococo e do pneumococo aos antimicrobianos. Revista da Sociedade Brasileira de Medicina Tropical, v.33, n.3, p. 281-301, 2000.

ZHANG; PORNPATTANANGUKUL; $\mathrm{H} . \quad \mathrm{U}$; HUANG. Development of Nanoparticles for Antimicrobial Drug Delivery. Current Medicinal Chemistry, v. 17, p. 585-594, 2010.

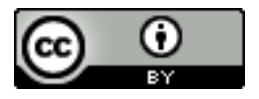

License information: This is an openaccess article distributed under the terms of the Creative Commons Attribution License, which permits unrestricted use, distribution, and reproduction in any medium, provided the original work is properly cited.

Artigo recebido em 11 de julho de 2016.

Avaliado em 29 de julho de 2017.

Aceito em 23 de agosto de 2017.

Publicado em 22 de setembro de 2017.

\section{Como citar este artigo (ABNT):}

COSTA, Anderson Luiz Pena da; SILVA JUNI-

OR, Antonio Carlos Souza. Resistência bacteriana aos antibióticos e Saúde Pública: uma breve revisão de literatura. Estação Científica (UNIFAP), Macapá, v. 7, n. 2, p. 45-57, maio/ago. 2017. 